\title{
Formulasi Krim Ekstrak Etanol Herba Krokot (Portulacca oleracea L.) sebagai Tabir Surya
}

\author{
Ani Hartati \\ Jurusan Farmasi, Politeknik Kesehatan Tanjung Karang, Indonesia \\ Email: anihartati2015@gmail.com
}

\begin{abstract}
Cream Formulation of Ethanol Extract of Purslane Herb (Portulacca oleracea L.) as a Sunscreen. The use of sunscreen is a way to prevent the adverse effects of sun exposure to the skin. Sunscreens that contain synthetic chemical compounds can cause allergies to the skin. Therefore it is necessary to look for other ingredients that have activities as sunscreens, one of which is by using natural ingredients, especially from plants such as purslane herbs that have these activities. This type of research is an experiment to formulate cream of ethanol extract of purslane herbs as sunscreens with concentrations of $0 \%, 0.5 \%, 0.75 \%$, and $1.0 \%$. The thick extract of purslane herb is formulated as a cream with a base of stearic acid cream, cetyl alcohol, glycerin, triethanolamine, with nipagin and nipasol preservatives. Furthermore, the cream was carried out several tests, namely organoleptic test, homogeneity, $\mathrm{pH}$, spreadability, stability, cream type, and SPF value in vitro. The test results found that the formulated cream had a light brown-green color, with a distinctive odor and half solid consistency. A cream that is made homogeneous, all creams are alkaline. All the spread cream meets the requirements (more than $4 \mathrm{~cm}$ ). All cream formulas are stable because there is no separation in the cycling test. This type of cream is a type of oil in water that is easy to wash. SPF value of F0 cream ( $0 \%$ purslane ethanol extract) was $0.620 \pm 0.070$, F2 $(0.5 \%$ extract $) \quad 4.341 \pm 0.565$, F3 $(0.75 \%$ extract $) 5.289 \pm 0.644$, and F3 (1.0\% extract) $7,862 \pm 1,564$.
\end{abstract}

Keywords: Cream, Ethanol extract of purslane herbs, Evaluation

\begin{abstract}
Abstrak: Formulasi Krim Ekstrak Etanol Herba Krokot (Portulacca oleracea L.) sebagai Tabir Surya. Penggunaan tabir surya merupakan suatu cara mencegah efek buruk paparan sinar matahari terhadap kulit. Tabir surya yang mengandung senyawa kimia sintesis dapat menyebab timbulnya alergi pada kulit. Oleh karena itu perlu dicari bahan lain yang mempunyai aktivitas sebagai tabir surya, salah satunya dengan menggunakan bahan alam terutama dari tumbuhan seperti herba krokot yang mempunyai aktifitas tersebut. Jenis penelitian adalah eksperimen dengan tujuan untuk memformulasi krim ekstrak etanol herba krokot sebagai tabir surya dengan konsentrasi 0\%, 0,5\%, 0,75\% dan 1,0\%. Ekstrak kental herba krokot diformulasikan sebagai krim dengan basis krim asam stearat, setil alkohol, gliserin, trietanolamin, dengan pengawet nipagin dan nipasol. Selanjutnya krim dilakukan beberapa pengujian, yaitu uji organoleptis, homogenitas, $\mathrm{pH}$, daya sebar, stabilitas, tipe krim dan nilai SPF in vitro. Hasil uji didapatkan krim yang telah diformulasi mempunyai warna hijau coklat muda, dengan bau yang khas dan konsistensinya setengah padat. Krim yang dibuat homogen, semua krim bersifat basa. Semua krim daya sebarnya memenuhi syarat ( lebih dari $4 \mathrm{~cm}$ ). Semua formula krim stabil karena tidak ada pemisahan pada freeze thaw test. Tipe krim adalah tipe minyak dalam air sehingga mudah dicuci. Nilai SPF krim

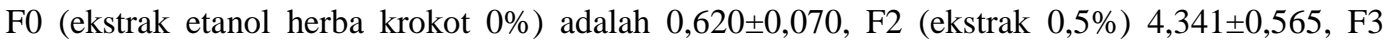

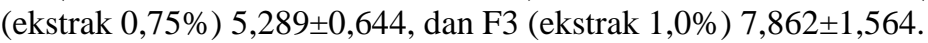

Kata kunci: Krim, Ekstrak etanol herba krokot, Evaluasi

\section{PENDAHULUAN}

Sebagai negara tropis, Indonesia setiap harinya mendapatkan paparan sinar matahari. Sinar matahari memang diperlukan untuk kesehatan. Namun, bila terlalu banyak paparan sinar matahari terutama di siang hari dapat menyebabkan terjadinya gangguan kesehatan terutama pada kulit. Efek buruk paparan sinar matahari dapat dicegah dengan cara menghindari paparan berlebihan sinar, yaitu tidak berada di luar rumah pada jam 10 pagi sampai 4 sore, memakai pelindung fisik seperti pakaian tertutup, payung, caping, dan memakai tabir surya (Perwitasari, dkk. 1999 dalam Pontoan, J, 2016). 
Penggunaan tabir surya merupakan salah satu cara untuk mengatasi efek yang ditimbulkan oleh paparan sinar UV terhadap kulit. Tabir surya adalah sediaan yang digunakan pada kulit untuk melindungi kulit dari efek yang berbahaya dari sinar ultra violet. Tabir surya bekerja dengan cara memantulkan, menyerap atau menghamburkan sebagian atau semua sinar UV.

Berdasarkan kandungannya, sediaan tabir surya dibedakan menjadi sunblock dan sunscreen. Sunblock bekerja memantulkan sinar UV dan pemakaiannya dioleskan tebal di kulit. Zat yang bersifat sunblock antara lain titanium oksida dan seng oksida. Sedangkan sunscreen bekerja menyerap sinar UV supaya tidak menyerang sel kulit (Trenggono, dkk., 2007).

Beberapa penelitian dilakukan untuk mengetahui dan mendapatkan tumbuhan yang mempunyai kemampuan sebagai tabir surya Penelitian tersebut telah dilakukan dengan menguji ekstrak atau minyak dari beberapa tumbuhan, antar lain lidah buaya (Aloe vera), belustru (Luffa cylindrica), lada panjang (Piper longum) dan malaka (Emblica officinalis) (Sanja dalam Ismail, I, 2013).

Penelitian yang dilakukan oleh Lolo, WS, dkk., 2017 didapatkan hasil bahwa ekstrak etanol herba krokot mempunyai nilai SPF 19,5. Krokot mengandung $\mathrm{KCl}, \mathrm{K}_{2} \mathrm{SO}_{4}, \mathrm{KNO}_{3}$, asam nikotinat, saponin, vitamin $\mathrm{A}, \mathrm{B}$, dan $\mathrm{C}$, noradrenalin, 1noradrenalin, dopamin dan dopa. Sedangkan menurut Materia Medika Indonesia, herba krokot mengandung saponin, steroid/triterpenoid, karoten, vitamin $\mathrm{C}, \mathrm{B}_{1}, \mathrm{~B}_{2}, \mathrm{Ca}, \mathrm{Mg}$, asam organik, glikosida glikoretin (Depkes RI, 1995).

Efektifitas suatu zat atau produk sebagai tabir surya dinyatakan dalam SPF (Sun Protection Factor). Nilai SPF yang tinggi menunjukkan perlindungan kulit dari sinar UV (UV-A atau UV-B) semakin besar.

Penelitan ini bertujuan untuk membuat formulasi krim yang mengandung ekstrak etanol herba krokot serta melakukan evaluasi dari krim yang dibuat meliputi sifat organoleptis, homogenitas, $\mathrm{pH}$, daya sebar, stabilitas, tipe krim, dan nilai SPF in viro.

Penelitian ini bermanfaat untuk mengetahui nilai SPF dari masing-masing krim sehingga selanjutnya dapat dikembangkan menjadi produk tabir surya yang memenuhi persyaratan.

\section{METODE}

Jenis penelitian ini adalah eksperimental dengan post control group design, yang sebelumnya telah lolos kaji etik melalui Komisi Etik Penelitian Politeknik Kesehatan Tanjung Karang dengan nomor 81/EC/KEP-TJK/V/2018.

Terdapat empat kelompok perlakuan yaitu formulasi krim yang mengandung ekstrak etanol herba krokot $0 \%$ sebagai kontrol dan tiga formula krim yang mengandung ekstrak etanol herba krokot (Portulaca oleracea L.) dengan konsentrasi masing-masing $0,5 \%, 0,75 \%$ dan $1,0 \%$. Masing-masing konsentrasi dibuat replikasi enam kali sehingga terdapat 24 sampel yang diuji.

Bahan yang digunakan herba krokot didapatkan di sekitar tempat tinggal di daerah Metro, etanol 96\%, pereaksi Mayer, Dragendorff, Bouchardat, $\mathrm{FeCl}_{3} 5 \%, \mathrm{HCl}$, asam stearat, trietanolamin, gliserin, setil alkohol, nipagin, nipasol, metilen blue. Sedangkan alat yang digunakan adalah bejana maserasi, rotary evaporator, $\mathrm{pH}$ meter, oven, spektrofotometer, waterbath, lemari pendingin.

Pembuatan ekstrak etanol herba krokot dibuat dengan merendam 350 gram serbuk herba krokot kering dalam etanol 96\% (1:5) selama $3 \times 24$ jam dan tiap 8 jam dilakukan pengadukan. Setelah disaring, ampas direndam kembali dengan sejumlah etanol yang sama selama $3 \times 24$ jam. Setelah disaring, maserat diuapkan sampai didapatkan ekstrak kental.

Penapisan fitokimia ekstrak dilakukan untuk mengetahui ada tidaknya alkaloida, flavonoida, tanin, saponin, dan steroida dalam ekstrak yang didapat.

Alkaloida: Ekstrak setara dengan 0,5 g serbuk simplisia ditambahkan $1 \mathrm{ml}$ asam klorida $2 \mathrm{~N}$ dan $9 \mathrm{ml}$ air suling, dipanaskan di atas tangas air selama 2 menit, didinginkan lalu disaring. Tiga tetes filtrat ditambahkan dua tetes pereaksi Mayer, tiga tetes filtrat berikutnya ditambahkan dua tetes pereaksi Bouchardat, dan tiga tetes filtrat Dragendorff. Positif mengandung alkaloid bila terdapat kekeruhan bahkan endapan pada dua dari tiga pereaksi yang digunakan.

Flavonoida: Ekstrak setara dengan 1 gram serbuk simplisia dilarutkan dalam etanol $95 \%$. Larutan ekstrak ditotolkan pada plat KLT Silika gel lalu dieluasi dengan eluen metanol air (4:1). Selanjutnya plat dikeringkan kemudian diberi uap amoniak. Positif mengandung alkaloid jika terdapat noda kuning.

Tanin: Ekstrak setara dengan 0,5gr serbuk simplisia disari dengan $10 \mathrm{~mL}$ air suling. Settelah disaring, filtrat diencerkan dengan air suling sampai tidak berwarna, diambil $2 \mathrm{ml}$ larutan lalu ditambahkan 1 sampai 2 tetes pereaksi besi (III) klorida. Positif mengandung tanin bila terbentuk warna hijau atau biru kehitaman. 
Saponin: Ekstrak setara dengan 0,5gr serbuk simplisia dimasukkan ke dalam tabung reaksi dan ditambahkan $10 \mathrm{ml}$ air suling panas, didinginkan, kemudian dikocok kuat-kuat selama 10 detik. Positif mengandung saponin bila terbentuk buih yang bertahan selama sepuluh menit.

Steroida: Ekstrak setara dengan 1 gr serbuk simplisia dimaserasi dengan $20 \mathrm{ml} \mathrm{n}$ heksan selama 2 jam, lalu disaring, filtrat diuapkan dalam cawan penguap, residu ditambahkan 2 tetes asam asetat anhidrat dan 1 tetes asam sulfat pekat. Positif mengandung steroida bila terbentuk warna ungu atau merah yang kemudian berubah menjadi hijau biru.

Pembuatan krim yang mengandung ekstrak etanol herba krokot menggunakan formula seperti pada tabel berikut :

Tabel 1. Formula Krim Tabir Surya yang Mengandung Ekstrak Etanol Herba Krokot (dalam \%)

\begin{tabular}{lrrrr}
\hline Komposisi & F0 & \multicolumn{1}{c}{ F1 } & \multicolumn{1}{c}{ F2 } & \multicolumn{1}{c}{ F3 } \\
\hline Asam stearat & 12 & 12 & 12 & 12 \\
Setil alkohol & 0,2 & 0,2 & 0,2 & 0,2 \\
Nipasol & 0,08 & 0,08 & 0,08 & 0,08 \\
Ekstrak & 0 & 0,5 & 1,0 & 1,5 \\
Trietanolamin & 2 & 2 & 2 & 2 \\
Gliserin & 10 & 10 & 10 & 10 \\
Nipagin & 0,1 & 0,1 & 0,1 & 0,1 \\
Akuades ad & 100 & 100 & 100 & 100 \\
\hline
\end{tabular}

Asam stearat, setil alkohol, dan propil paraben dilebur sampai suhu $70^{\circ} \mathrm{C}$ lalu diaduk (fasa minyak), Trietanolamin, metil paraben dan akuades dipanaskan sampai suhu $70^{\circ}$ sampai $75^{\circ} \mathrm{C}$ lalu diaduk (fasa air). Fasa air dimasukkan ke fasa minyak sedikit demi sedikit sampil diaduk cepat dengan bantuan mixer lalu didinginkan kemudian dicampur dengan ekstrak etanol herba krokot yang sudah diencerkan dengan sisa akuadest dengan bantuan mikser.

\section{Pemeriksaan Kualitas Krim}

Organoleptis, pemeriksaannya meliputi pengamatan bau, warna dan konsistensi dari sediaan krim (Widodo, 2013) dengan bantuan 15 panelis.

Homogenitas, dengan mengoleskan sejumlah lebih kurang 0,1 gram krim pada gelas obyek dan diamati secara visual ada tidaknya partikel kasar (Depkes RI, 1979).

$\mathrm{pH}$, dengan cara mengencerkan 1 bagian krim dalam 10 bagian akuades, setelah diaduk rata dan didiamkan sebentar diukur menggunakan pH-meter.
Daya sebar krim ditentukan dengan mengambil 1gram krim dan diletakkan di atas kaca. Kemudian krim ditimpa dengan kaca ukuran $20 \times 20 \mathrm{~cm}$ dan diberi pemberat sehingga berat totalnya $125 \mathrm{gr}$. Dicatat diameter krim yng tersebar (Garg, A, et al., 2002)

Stabilitas krim diuji menggunakan metode freeze thaw dengan cara.menyimpannya dalam oven suhu $40^{\circ} \mathrm{C}$ selama 24 jam lalu dimasukkan ke pendingin suhu $0^{\circ}$ selama 24 jam (satu siklus). Kemudian diulang kembali sampai enam siklus.

Tipe krim, ditentukan dengan pengenceran dengan air dan pewarnaan menggunakan metilen blue (Syamsuni, 2007).

\section{Penentuan Nilai SPF (Sun Protection Factor) in Vitro}

Nilai SPF ditentukan secara in vitro menggunakan spektrofotometri (Pissavini dalam Purwaningsih, S, dkk., 2015) dengan menimbang 0,5 gram krim secara teliti lalu dilarutkan dalam etanol $(96 \%)$ dan dimasukkan ke dalam labu takar 50mL. Ditentukan absorbansinya pada $\lambda$ $290 \mathrm{~nm}$ sampai $320 \mathrm{~nm}$ dengan interval $5 \mathrm{~nm}$.

Nilai SPF ditentukan setelah memasukkan ke persamaan berikut :

$$
\operatorname{SPF}=\operatorname{CF} \times \Sigma_{290}^{320} \operatorname{EE}(\lambda) \times \mathrm{I}(\lambda) \times \text { Absorbansi }(\lambda)
$$

\section{HASIL}

Berdasarkan penapisan fitokimia, diketahui bahwa ekstrak etanol herba krokot mengandung saponin dan steroid. Sedangkan uji organoleptis dan homogenitas yang dilakukan oleh 15 panelis didapatkan hasil sebagai berikut

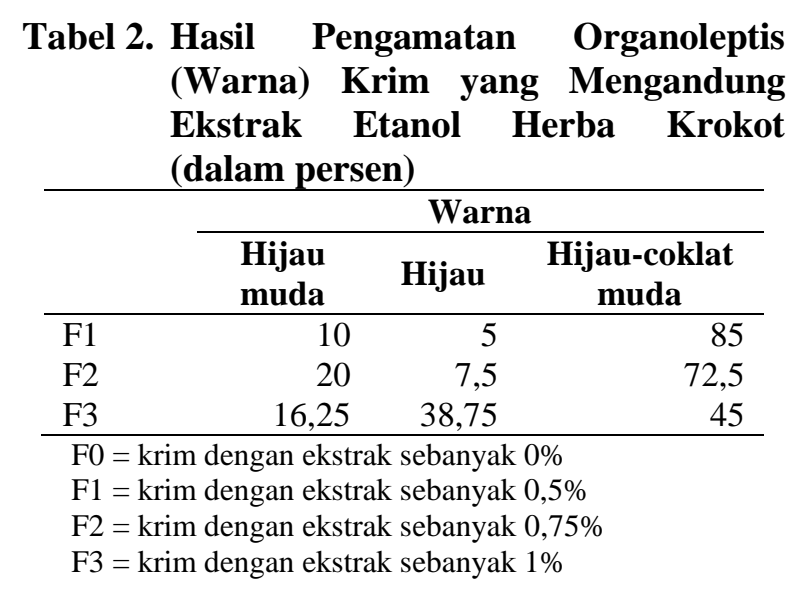


Tabel 3. Hasil Pengamatan Organoleptis (Bau dan Konsistensi) Krim yang Mengandung Ekstrak Etanol Herba Krokot (dalam persen)

\begin{tabular}{rrrrr}
\hline & \multicolumn{2}{c}{ Bau } & \multicolumn{2}{c}{ Konsistensi } \\
\cline { 2 - 5 } & $\begin{array}{c}\text { Tidak } \\
\text { berbau }\end{array}$ & $\begin{array}{c}\text { Setengah } \\
\text { padat } \\
\text { agak cair }\end{array}$ & \multicolumn{1}{c}{$\begin{array}{c}\text { Setengah } \\
\text { padat }\end{array}$} & $\begin{array}{c}\text { Tidak } \\
\text { berbau }\end{array}$ \\
\hline F0 & 78,75 & 21,25 & 38,75 & 61,25 \\
F1 & 22,5 & 77,5 & 26,25 & 73,75 \\
F2 & 8,75 & 91,25 & 15 & 85 \\
F3 & 8,75 & 91,25 & 31,25 & 68,75 \\
\hline
\end{tabular}

Tabel 4. Hasil Pengamatan Homogenitas Krim yang Mengandung Ekstrak Etanol Herba Krokot (dalam persen)

\begin{tabular}{|c|c|c|}
\hline Formula Krim & Homogen & $\begin{array}{c}\text { Tidak } \\
\text { Homogen }\end{array}$ \\
\hline F0 & 96,25 & 3,75 \\
\hline F1 & 95 & 5 \\
\hline F2 & 96,25 & 3,75 \\
\hline F3 & 93,75 & 6,25 \\
\hline
\end{tabular}

Tabel 5. pH Sediaan Krim Tabir Surya yang Diformulasikan dengan Ekstrak Etanol Herba Krokot

\begin{tabular}{lr}
\hline Formula & \multicolumn{1}{c}{ pH } \\
\hline F0 $(0 \%$ ekstrak $)$ & $8,12 \pm 0,08$ \\
F1 $(0,5 \%$ ekstrak $)$ & $7,92 \pm 0,04$ \\
F2 $(0,75 \%$ ekstrak $)$ & $7,9 \pm 0,0$ \\
F3 $(1,0 \%$ ekstrak $)$ & $7,82 \pm 0,04$ \\
\hline
\end{tabular}

Tabel 6. Tabel Diameter (cm) Area Krim yang Diberi Beban

\begin{tabular}{cr}
\hline Formula & Diameter rata-rata \\
\hline F0 & $5,15 \pm 0,59 \mathrm{~cm}$ \\
F1 & $5,67 \pm 0,73 \mathrm{~cm}$ \\
F2 & $4,96 \pm 0,52 \mathrm{~cm}$ \\
F3 & $4,69 \pm 0,22 \mathrm{~cm}$ \\
\hline
\end{tabular}

Seluruh formul krim yang dibuat stabil selama proses cycling test.

\begin{tabular}{cr}
$\begin{array}{c}\text { Tabel 7. Hasil } \\
\text { Ekstrak Etanol Herba Krokot }\end{array}$ & $\begin{array}{c}\text { Pengujian Nilai } \\
\text { SPF }\end{array}$ \\
\hline Formula & Kilai SPF rata-rata \\
\hline F0 & $0,620 \pm 0,070$ \\
F1 & $4,341 \pm 0,565$ \\
F2 & $5,289 \pm 0,644$ \\
F3 & $7,862 \pm 1,564$ \\
\hline
\end{tabular}

\section{PEMBAHASAN}

Ekstrak etanol herba krokot berdasarkan skrining fitokimia mengandung saponin dan senyawa terpenoid steroid. Hal ini sesuai dengan literatur bahwa herba krokot mengandung saponin dan steroid triterpenoid (Depkes RI, 1995).

Berdasarkan hasil pengujian organoleptis, sebagian besar responden menyatakan bahwa warna krim adalah hijau coklat muda. Warna hijau coklat muda adalah warna yang dihasilkan dari ekstrak etanol herba krokot. Meskipun ekstrak yang digunakan cukup kecil (maksimal $1,0 \%)$ namun warna yang dihasilkan memberi warna yang intensif pada krim. Warna hijau berasal dari klorofil dan coklat dapat disebabkan oleh warna dari batangnya yang merah kecoklatan. Formula yang mengandung 0\% ekstrak tidak diikutkan dalam pengamatan karena tidak dipengaruhi oleh warna ekstrak. Warna formula F0 adalah warna dasar sediaan.

Penambahan ekstrak etanol herba krokot pada krim memberikan bau khas pada krim tersebut. Makin besar konsentrasi ekstrak yang ditambahkan maka makin berbau sediaan krim tersebut.

Sediaan krim yang diformulasikan dengan ekstrak etanol herba krokot menghasilkan sediaan yang konsistensinya setengah padat. Bila dilihat dari tabel 4.2 atau gambar 4.3 tampak F0 dan F3 dinyatakan setengah padat agak cair. Maksudnya adalah cenderung lebih lunak bila dibandingkan dengan setengah padat yang biasa. Dari penelitian didapatkan bahwa peningkatan kadar ekstrak tidak mempengaruhi konsistensi krim yang dihasilkan.

Homogenitas dari sediaan tidak jauh berbeda, hanya pada krim yang mengandung konsentrasi ekstrak yang lebih tinggi dipandang lebih tidak homogen. Hal ini dapat terjadi karena yang digunakan adalah ekstrak kental yang ketika dicampur peneliti mengalami sedikit kesusahan untuk menghomogenkannya.

Keeempat formula krim memiliki $\mathrm{pH}$ sediaan yang basa $(\mathrm{pH}>7)$. Dengan demikian krim tidak memenuhi persyaratan $\mathrm{pH}$ kulit yaitu 4,5-6,5 (Trenggono, dkk.,2007). Formula F0 yang tidak mengandung ekstrak etanol herba krokot mempunyai $\mathrm{pH}$ paling tinggi. $\mathrm{pH}$ cenderung menurun dengan semakin meningkatnya konsentrasi ekstrak pada krim tersebut. $\mathrm{pH}$ basa dari sediaan krim disebabkan oleh adanya emulgator yang digunakan, yaitu TEA (trietanolamin) yang bersifat basa. Ekstrak etanol herba krokot bersifat asam sehingga semakin banyak konsentrasinya dalam formula akan menurunkan $\mathrm{pH}$ krim.

Krim memiliki daya sebar yang memenuhi syarat yaitu diameter ketika diberi tekanan tidak kurang dari $4 \mathrm{~cm}$. Dari tabel 5 tampak makin besar konsentrasi ekstrak maka makin kecil daya 
sebarnya. Seperti yang dinyatakan semula, bahwa ekstrak yang digunakan adalah ekstrak yang sangat kental dan secara orgnoleptis ketika ekstrak mengenai tangan ada rasa sangat lengket di tangan. Ketika dicuci, ekstrak agak sulit untuk dihilangkan.

Sediaan krim diuji stabilitasnya dengan meletakkan ke dalam oven dan lemari es secara bergantian selama enam kali. Ketika dikeluarkan dari oven, krim tampak lebih encer, ketika dikeluarkan dari lemari es, krim tampak lebih padat. Namun setelah didiamkan pada suhu kamar, krim tidak ada perubahan yang berarti dari segi fisiknya (organoleptis dan homogenitas).

Tipe krim yang terbentuk adalah emulsi tipe minyak dalam air. Krim tipe ini sangat mudah dicuci dengan air dan nyaman bila digunakan sebagai bahan dasar sediaan kosmetik.

Nilai SPF in vitro sebanding dengan kadar ekstrak yang ditambahkan. Nilai SPF tertinggi $7,862 \pm 1,564$, terdapat pada formula yang

\section{DAFTAR PUSTAKA}

Depkes RI. (1979). Farmakope Indonesia III, Jakarta.

Depkes RI (1995). Materia Medika Indonesia ed.VI, Jakarta.

Garg, A, et. al. (2002). Spreading of Semisolid Formulation. USA Pharmaceutical Technology.

Ismail, I. (2013). Potensi Bahan Alam Sebagai Bahan Aktif Kosmetik Tabir Surya. Jurnal Farmasi UIN Alauddin Makassar, 1:1, h. $45-55$

Lolo, WA, S Sudewi dan HJ Edy. (2017). Penilaian Nilai Sun Protecting Factor (SPF) Herba Krokot (Portulaca oleracea L.). Journal of Pharmaceutical Science and Clinical Research, 02, h.1-5.

Pontoan, Jenny. (2016). Uji Aktivita Antioksidan dan Tabir Surya dari Ekstrak Daun mengandung $1 \%$ ekstrak, terendah pada formula yang mengandung $0 \%$ ekstrak. Formula dengan 0\% ekstrak juga mempunyai nilai SPF meskipun keci $(0,620 \pm 0,070)$, ini berarti basis krim mengandung bahan yang mempunyai aktiitas sebagai tabir surya.

\section{SIMPULAN}

Berdasarkan dari hasil yang didapat, dapat disimpulkan bahwa krim yang mengandung ekstrak etanol herba krokot memberikan bau yang khas, warna dominan hijau coklat muda dan konsistensi krim setengah padat, dan homogen. Semua krim memiliki pH basa dengan daya sebar yang memenuhi persyaratan. Krim yang dihasilkan tipenya $o / w$. yang mengandung ekstrak etanol herba krokot menghasilkan krim yang homogen. Makin tinggi kadar ekstrk etanol herba rokot maka makin besar nilai SPF in vitronya.

\begin{abstract}
Alpukat (Persea americana, M.). Indonesia Natural Research Pharmaceutical Journal I: 1. Jakarta: Universitas 17 Agustus 1945, h. 55-66.
\end{abstract}

Purwaningsih, S, E Salamah, dan M Nur Adnin, (2015). Efek Fotoprotektif Krim Tabir Surya dengan Penambahan Karaginan dan Buah Bakau Hitam (Rhizopus mucronata Lamk.). Jurnal Ilmu dan Teknologi Kelautan, 7:1, h.1-14.

Syamsuni, HA. (2007). Ilmu Resep. Jakarta: Penerbit Buku Kedokteran EGC.

Trenggono, Retno Iswari, dan Fatimah Latifah, (2007). Buku Pegangan Ilmu Pengetahuan Kosmetik. Jakarta: PT Gramedia Pustaka Utama.

Widodo, Hendra. (2013). Ilmu Meracik Obat untuk Apoteker. Yogyakarta:D-Medika. 